\title{
Influence of surface roughness on heat transfer during quenching hot metals with different nozzles
}

\author{
Yuan Fang $^{1} \cdot$ Hermann Woche ${ }^{1} \cdot$ Eckehard Specht $^{1}$ \\ Received: 27 August 2019 / Accepted: 27 March 2020 / Published online: 17 April 2020 \\ (C) The Author(s) 2020
}

\begin{abstract}
The experimental work aims at investigating the influence of surface roughness on heat transfer by using different nozzles. Part of the rough surfaces are provided directly by the industry. These surfaces of casting products possess considerable roughness up to millimeters which can be either unstructured or with typical grooves in the casting direction. The understanding of its effect on cooling hot metals can help to shed light on the quenching process encountered in the industrial applications. This study will initially be carried out with individual nozzles, such as full cone and full jet nozzles, in order to identify the basic relations. Subsequently, a mold is also applied which can be regarded as a series of full jet nozzles. As for the experiments with mold, the plate is moving downwards with a preset velocity; meanwhile, the plate is fixed for experiments with full jet and full cone nozzle.
\end{abstract}

\section{Introduction}

Quenching or rapid cooling refers to the process which frequently occur during metallurgical processes. In these processes, the maximum temperature can reach $500{ }^{\circ} \mathrm{C}$ or much higher. Cooling processes include pool boiling, impingement of liquid jets or sprays [1]. Pool boiling and liquid jets provide high heat dissipation rates, while a better spatial uniformity of the cooling can be achieved by using sprays.

Cooling with liquid jets and sprays has been studied extensively in the past few decades. Many variables are included in both numerical and experimental investigations. For example, it is usually accepted that the spray flux (also names as impingement density or volumetric flux) is the most influential parameter during cooling hot surfaces with liquid sprays [1-3]. As for liquid jets, the jet velocity and liquid temperature are seen as primary variables which control the cooling efficiency. Karwa and Stephan [4] found out the wetting front velocity increases as jet velocity increases while it is reducing as the wetting front moves radially to the circumferential area. Wang et al. [5] reported that the rewetting temperature was not susceptible to the jet velocity, which is in congruence with results obtained by Lee and Shen [6]. The both articles

Yuan Fang

yuan.fang@ovgu.de

1 Otto von Guericke University, 39106 Magdeburg, Germany suggested that the rewetting temperature was almost independent of $v_{j} \Delta T_{\text {sub }}$. Mozumder et al. [7] have reported maximum heat flux as a function of jet subcooling during quenching a hot cylinder with different experimental conditions. It was shown that a higher maximum heat flux can be achieved with a higher liquid subcooling.

During the cooling of hot metals, the surface condition or roughness is important to determine the heat transfer rate, which controls both physical and mechanical properties of the final product. The investigation of surface roughness on cooling performance has been done several authors and groups. To the best knowledge of the author, it was first reported by Pais et al. [8] that surface roughness has influence on air-atomized water spray cooling of copper surfaces. They proposed a one-dimensional Fourier analysis to retrieve the information of the surface morphology. Meanwhile, the ability of surface to remove heat under conditions of spray cooling using air-atomized nozzles was studied. It was reported, at very low superheats, a heat flux of $12 \mathrm{MW} / \mathrm{m}^{2}$ was achieved. They also found out that a superior cooling performance was achieved when the surface was smooth $(<1 \mu \mathrm{m})$ due to the film conduction/evaporation. Bernardin and Mudawar [9] have reported that repeated heat-quench cycles resulted in increased surface roughness and shorter overall quench periods. The surface roughness affects cooling rate by three major factors: a) raising the rewetting temperature, b) increasing the number of boiling sites on the quenched surface, and c) the impact dynamics of the spray droplets was altered. Sinha et al. [10] studied the effect of surface roughness on the minimum 
Fig. 1 Schematic of experimental setup

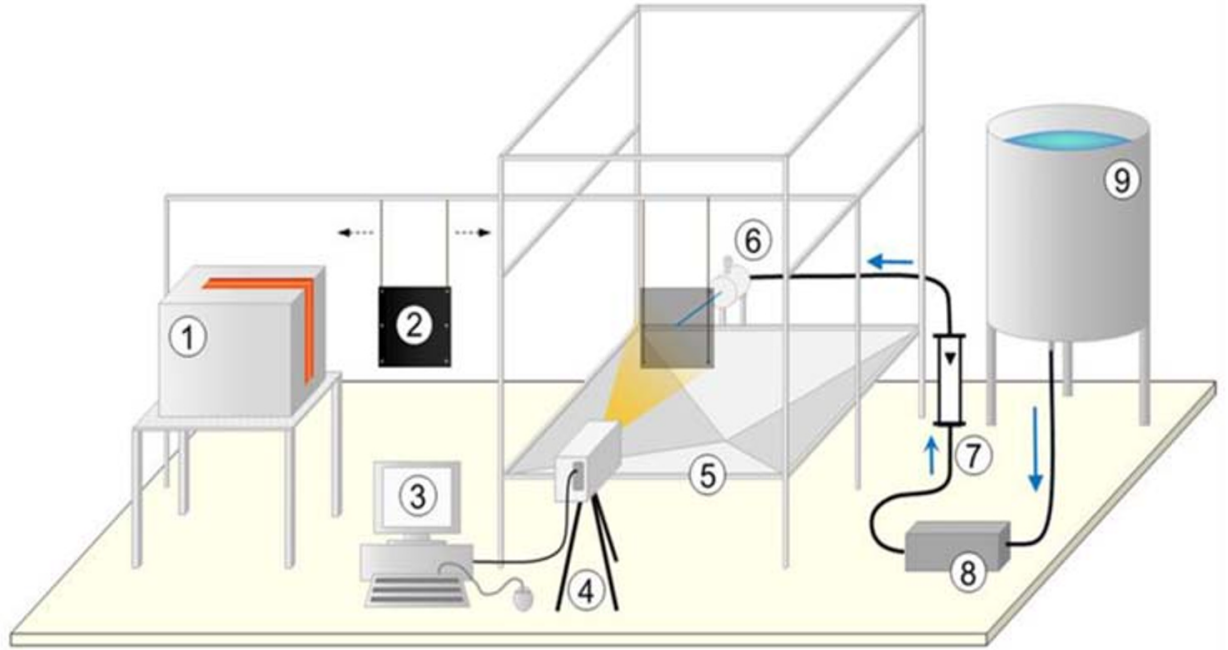

1. Furnace, 2. Metal Sample, 3. PC, 4. Infrared camera, 5. Cooling chambe, 6. Nozzle with pressure gauge, 7. Flowmeter, 8 . Pump system, 9. Water tank with heating function film boiling temperature (in this article named as rewetting temperature). A cylindrical fuel-rod simulator was heated up in an electrical furnace with a maximum temperature capability of $1200^{\circ} \mathrm{C}$. A profilometer was used to determine the rootmean-square (RMS) roughness levels. The unroughened rod from the manufacturer with RMS of $1.27 \mu \mathrm{m}$ was compared with the rods polished by 80 -grit sandpaper $(3.81 \mu \mathrm{m})$ and $40-$ grit sandpaper $(6.604 \mu \mathrm{m})$. The results showed that the influence of the roughness is significant. With increasing surface roughness, the minimum film boiling point is shifted from $420{ }^{\circ} \mathrm{C}$ to $520^{\circ} \mathrm{C}(3.81 \mu \mathrm{m})$ and $560{ }^{\circ} \mathrm{C}(6.604 \mu \mathrm{m})$, respectively. Meanwhile, the maximum heat flux doubled when the surface roughness increased from $1.27 \mu \mathrm{m}$ to $6.604 \mu \mathrm{m}$. The influence of roughness on fully developed film boiling was small, because the thickness of vapor layer was typically larger that the height of rough elements on the surface. The influence of artificially structured surfaces such as cubic pin fins, pyramids, and straight fins on the heat transfer has been studied by Silk et al. [11, 12]. In addition, a plain surface is used as reference. It should be emphasized that, unlike micro coatings, the characteristic dimensions of these structures are much larger than the liquid film thickness. The coolant used was a fully fluorinated liquid, $3 \mathrm{M}^{\mathrm{TM}}$ Performance Fluid PF5060 , with a boiling point of $56^{\circ} \mathrm{C}$. The initial temperatures were between 20 and $70{ }^{\circ} \mathrm{C}$. A copper surface of $2 \times 2 \mathrm{~cm}^{2}$ was cooled with a spray nozzle at a spray flux of $0,016 \mathrm{~m}^{3} /$ $\mathrm{m}^{2} \mathrm{~s}$. The distance of the nozzle to the copper surface was $17 \mathrm{~mm}$. It is reported that, the surface with pyramids was cooling most efficiently. Sodtke and Stephan [13] used highspeed infrared camera to study the water spray cooling for both smooth and micro-structured surfaces, the latter featuring micro pyramid with various heights. The spray flux is altering
Fig. 2 Investigated nozzle and mold
Full jet nozzle

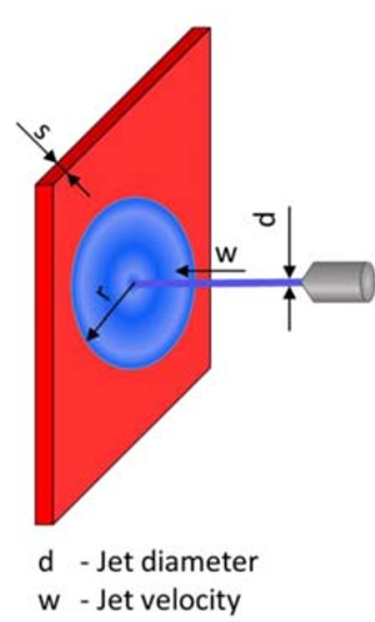

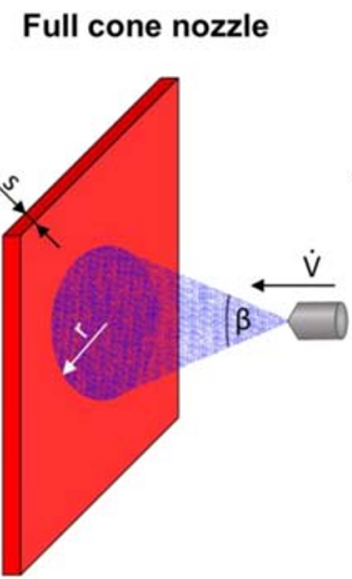

s - Sample thickness

$r$ - radius

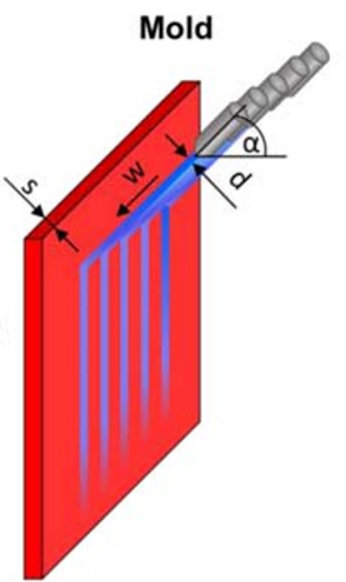

$\beta$ - Spray angle

$\dot{V}$ - Volume flow rate

$\alpha$ - Inclination angle 
Table 1 An overview of the investigated nozzles

\begin{tabular}{lll}
\hline Nozzle type & Nozzle designation according to Lechler & Features \\
\hline Full jet nozzle & 544.360 & Stainless steel, $\mathrm{d}=1.05 \mathrm{~mm}$ \\
& 544.400 & Stainless steel, $\mathrm{d}=1.3 \mathrm{~mm}$ \\
Full cone nozzle & 460.404 & Spray angle $\beta=60^{\circ}$ \\
\hline
\end{tabular}

by changing the nozzle-to-plate spacing. It was found out that a great improvement in cooling performance can be obtained with micro-structured surfaces, attributed to the increasing length of the three-phase contact line. The studies on the spray cooling of the aluminum alloy AA6082 was done by $\mathrm{Xu}$ et al. [14]. Three samples with roughness of $\mathrm{Ra}=0.6 / 7.6 / 40.2 \mu \mathrm{m}$ were investigated and compared. A surface with $R_{a}=0.6 \mu \mathrm{m}$ can be classified as technically smooth, with $R_{a}=40.2 \mu \mathrm{m}$ as very rough. It was reported, the surface roughness has a significant influence on heat flux in the nucleate boiling regime; however, its influence is small in the transition boiling regime. The authors argued that, the thickness of the intermittent vapor blanket in transient boiling regime is typically greater than any surface rough elements, which leads to the non-sensitivity of heat flux to the micro-surface geometry. The influence of surface roughness in the spray cooling of a stainless steel cylinder is studied by Aamir et al. [15]. Two cylinders made of stainless steel were used, one with pyramidal pin fins and other with smooth surface as a reference, to explore heat transfer performance under different spray conditions and surface temperatures. A spray nozzle with pressures of 4 to 13 bar and the corresponding mass flow rate of 13.5 to $23 \mathrm{~kg} / \mathrm{min}$ was used. Based on the diameter of $25 \mathrm{~mm}$, the average spray flux in the experiments is from 460 to $780 \mathrm{~kg} / \mathrm{m}^{2} \mathrm{~s}$ which indicates the used spray nozzle as a cooling-intensive nozzle. It was found out that, structured surface performed better at an initial temperature of $900{ }^{\circ} \mathrm{C}$ with a increment in surface heat flux by factor of 1.9, 1.56, 1.66 and 1.74 for inlet pressure of 0.4, 0.7, 1.0 and $1.3 \mathrm{MPa}$, respectively.

All the herein mentioned studies are limited to the investigation of heat transfer by using either artificial structures or rough surfaces produced by using various grit-level sandpapers. And they are mainly focused on utilization of spray nozzle. Therefore, the objective of the present work is to use the rough surfaces that directly cut from the industrial ingot to describe whether these surfaces exert influence on heat transfer during industrial quenching process or not. Meanwhile, an artificial surface is also produced in house for the purpose of comparison. Furthermore, different cooling methods are also included, they are full jet nozzle, full cone nozzle and mold.

\section{Experimental facility}

The experimental setup is schematically shown in Fig. 1. All essential apparatus and components are included in this illustration. An essential part of this facility is the sliding rail which allows the metal sample to be moved freely from the furnace to cooling chamber. The metal plate is mounted with two supporting rods to the sliding rail. Additionally, the rods are connected with two plastic sliders that are embedded in the rail. After being heated up to a desired initial temperature, the metal sample is moved into the cooling chamber. The heat loss, especially at a high initial temperature, is kept as low as
Fig. 3 Schematics of aluminum alloy samples cut from industrial ingots

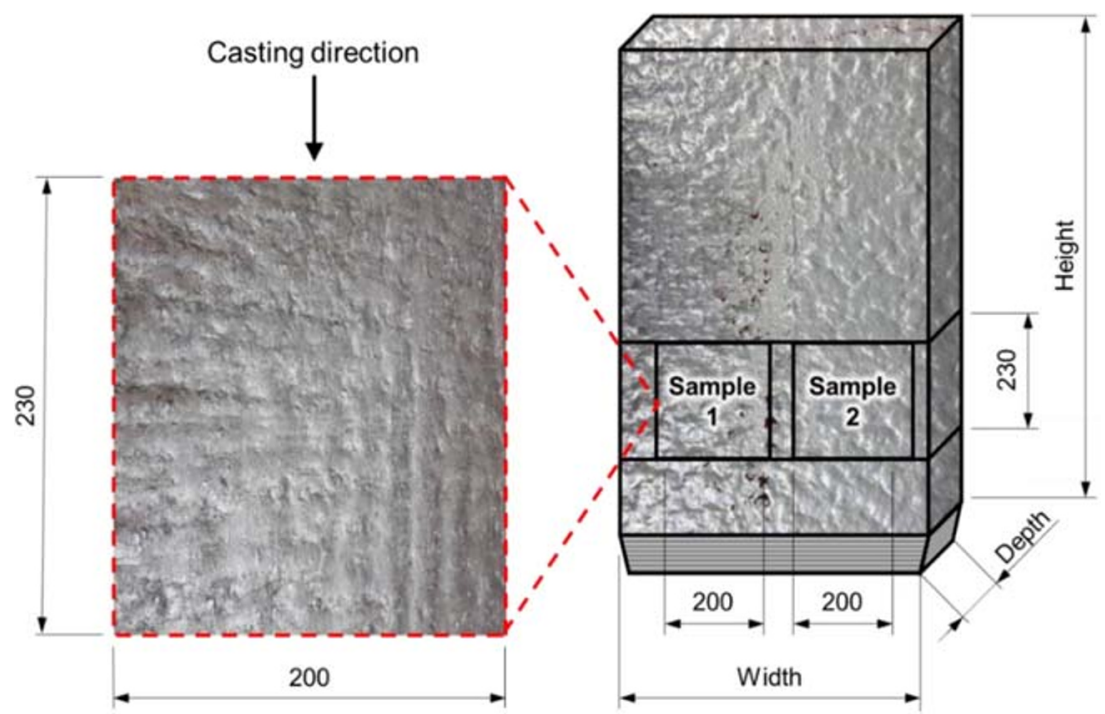


Fig. 4 Investigated rough surfaces from industrial suppliers

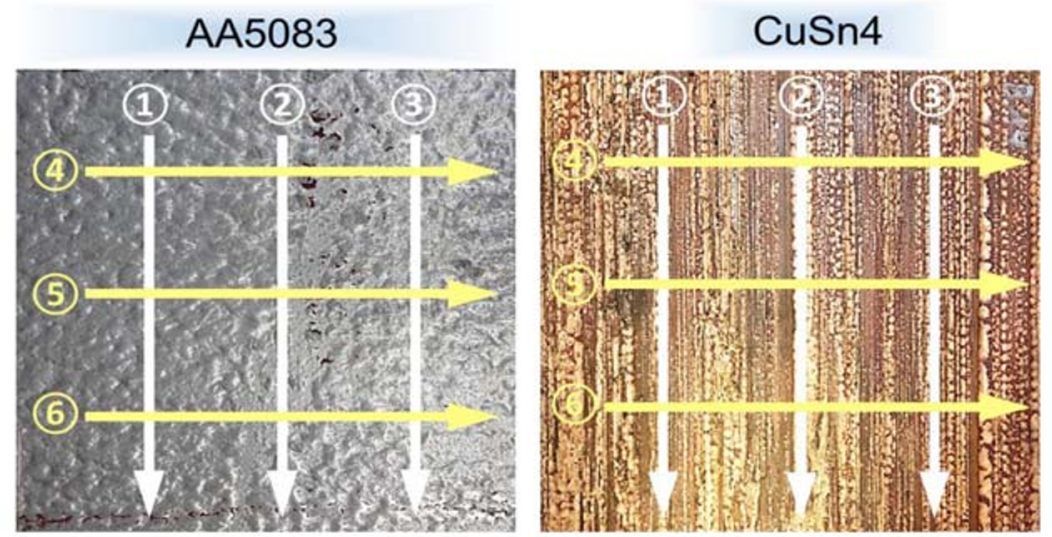

\begin{tabular}{|l|l|c|c|}
\hline \multicolumn{2}{|c|}{} & AA5083 & CuSn4 \\
\hline \multirow{2}{*}{ In casting direction (Linie 1-3) } & $\mathrm{R}_{\mathrm{a}}[\mu \mathrm{m}]$ & 46 & 15 \\
\cline { 2 - 4 } & $\mathrm{R}_{\mathrm{z}, \max }[\mu \mathrm{m}]$ & 97 & 529 \\
\hline \multicolumn{2}{|l}{} \\
\hline \multirow{2}{*}{$\begin{array}{l}\text { Perpendicular to casting } \\
\text { direction (Linie 4-6) }\end{array}$} & $\mathrm{R}_{\mathrm{a}}[\mu \mathrm{m}]$ & 44 & 95 \\
\cline { 2 - 4 } & $\mathrm{R}_{\mathrm{z}, \max }[\mu \mathrm{m}]$ & 300 & 412 \\
\hline
\end{tabular}

possible during the movement of the sample. The nozzle pressure is controlled with a manometer while the volume flow rate is monitored by a magnetic flowmeter. The liquid from the nozzle is initially reflected by a deflector between the nozzle and the hot sample which prevents the water jet from touching the heated metal sample. The installed deflector works with the principle of a guillotine and is operated by a rigid rope.

The data acquisition system consists of an infrared (IR) camera connected to a computer. In current work, infrared camera 'ThemaCAM SC 3000', produced by FLIR systems Inc., was used. This camera provides the ability to measure temperature with different quality by varying the measuring frequencies and temperature ranges. Four temperature ranges

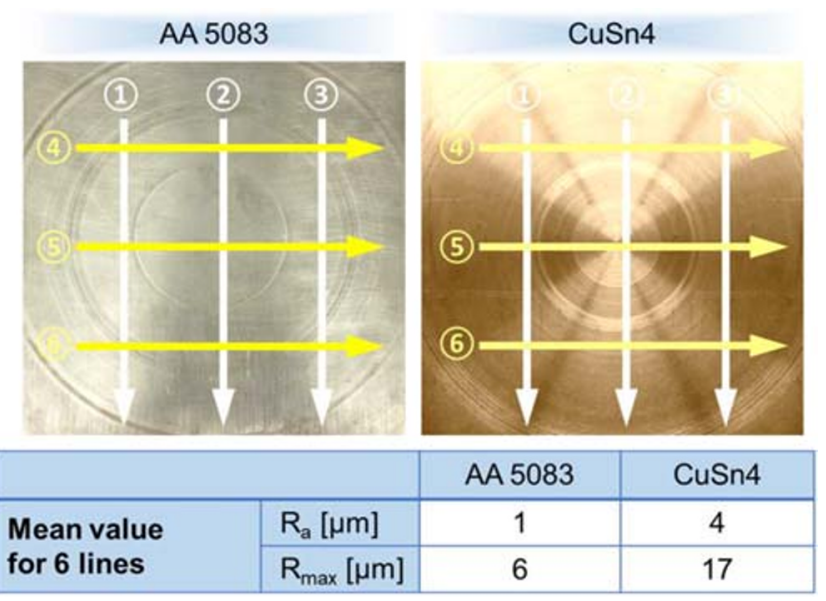

Fig. 5 The smooth surfaces produced through milling
( -20 to $80{ }^{\circ} \mathrm{C}, 10$ to $150{ }^{\circ} \mathrm{C}, 100$ to $500{ }^{\circ} \mathrm{C}$ and 350 to $1500{ }^{\circ} \mathrm{C}$ ) can be selected with four options of the desired frequency $(50,150,250$ and $750 \mathrm{~Hz})$. Noting that, when a higher frequency is chosen, the size of the thermal image will be smaller. For example, when $50 \mathrm{~Hz}$ is selected, the full resolution of this infrared camera $(320 \times 240$ pixel $)$ can be reached; while for $150 \mathrm{~Hz}$, the maximum resolution is reduced to $80 \times 320$ pixels. For the purpose of accuracy and suitability, all the measurements in this work have been carried out with a frequency of $50 \mathrm{~Hz}$, with which 50 thermal photos can be taken in $1 \mathrm{~s}$. The installation of the cooling chamber prevents the uncontrolled spreading of the liquid droplet which might deteriorate the thermal image quality. In addition, the resulting vapor during the quenching process is held in the chamber and thus does not reach the receiving area of the camera lens. The discussion of measurement accuracy of applied infrared thermography is detailed in Fang [16]. Furthermore, in order to achieve stable emissivity, the thermal spray is also employed, and the detail description of emissivity measurement is found in Fang [17]. Generally, the surface emissivity of the thermal coating is 0.85 for initial temperature of $500{ }^{\circ} \mathrm{C}$. The nozzle spacing to the metal sample being tested can also be easily adjusted. In present work, the nozzle-to-sample spacing is held $50 \mathrm{~mm}$ for full cone and full jet nozzle, while $8 \mathrm{~mm}$ for mold. The schematic of the used nozzle and mold is depicted in Fig. 2 and their specifications are listed in Table 1. A full jet nozzle produces the impinging jet with a diameter $d$ which strikes on the hot surface. A full cone nozzle theoretically produces a uniform circular area. The mold has totally 11 orifices, each with $2 \mathrm{~mm}$ in diameter. The distance between 
Fig. 6 Produced artificial surfaces with cubic pin structure

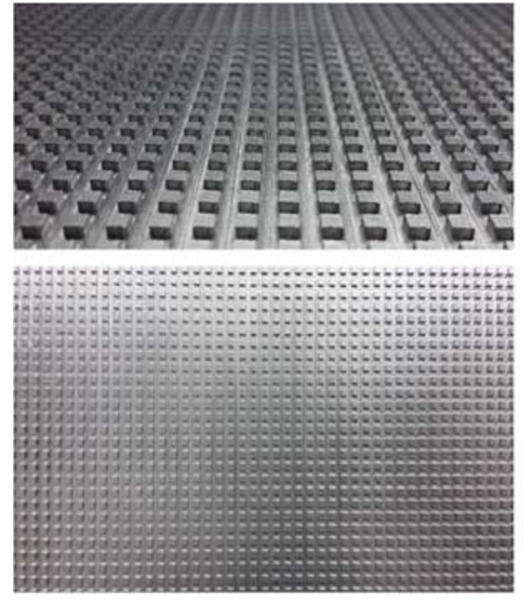

Aluminum alloy 6082

Size: $250 \times 230 \mathrm{~mm}$

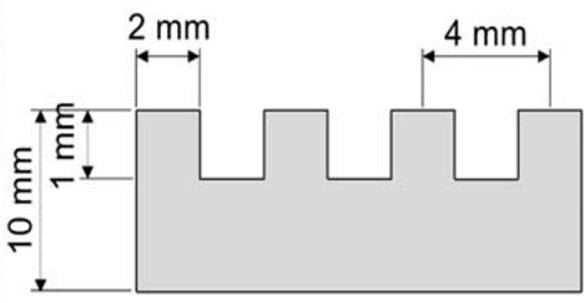

the centers of orifices is $6 \mathrm{~mm}$. A water curtain will be formed and then flow vertically on the surface due to gravity.

\subsection{Characteristics of the used surface}

The surface roughness of the utilized samples was measured according to DIN EN ISO 4288 at the Institute of Production Technology and Quality Management (IFQ) at the University of Magdeburg. A stylus-type surface roughness measuring instrument was used. The arithmetic mean roughness $R_{a}$, the maximum valley depth $R_{v}$, the maximum height of the profile $R_{t}$, the average distance between the highest peak and lowest valley in each sampling length $R_{z}$ and the maximum single roughness $R_{\max }$ were determined.

$R_{a}$ is the arithmetic average value of filtered roughness profile determined from the deviations about the center line and will be used as indication of the surface roughness in all the following figures. According to paperback "Dubbel" [18], surfaces with an arithmetic mean roughness below $0.1 \mu \mathrm{m}$ are classified as very smooth and those over $25 \mu \mathrm{m}$ as very rough.
As mentioned, the investigated surfaces are cut directly from the industrial ingot. The principle of sample extraction from ingots of aluminum alloys is shown in Fig. 3, which is quite similar for copper alloys. The surface should under no circumstances be damaged. Based on visual observation, casting direction can be easily recognized and roughness in the casting direction is less than that in transverse direction which will be documented in Fig. 4.

In order to compare the cooling effect on real rough surfaces with smooth surfaces, smooth samples of copper and aluminum alloys were produced through milling in our own lab, originating from the same batch of material. The production ensures that the smooth sample has the similar specific mass in $\mathrm{g} /$ unit area as the rough surface. Figure 5 shows the produced samples and the determined roughness parameters. Generally, depending on the alloy and surface treatment, the produced smooth surfaces for the cooling tests have $\mathrm{R}_{\mathrm{a}}$ values between 1 and $4 \mu \mathrm{m}$.

Similar to the experimental investigation of Silk et al. [11], a surface with cubic pin fins is also produced in our lab, which
Fig. 7 Visual representation of repeated cooling cycles with video and infrared images at a certain cooling time of $9 \mathrm{~s}$
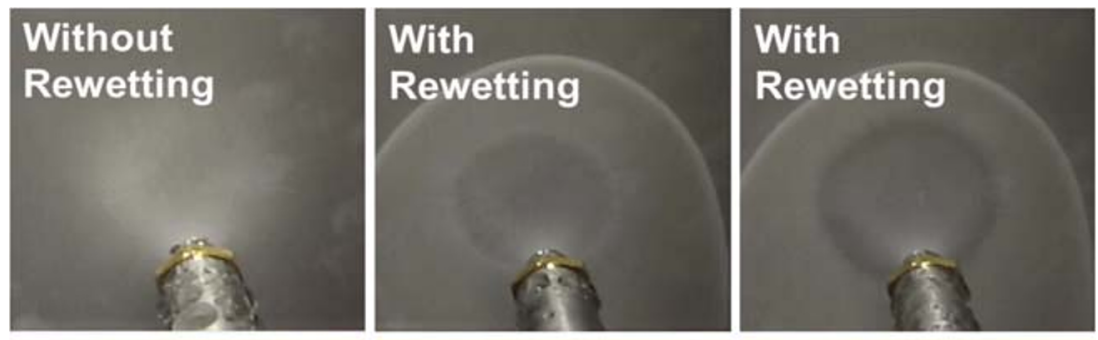

Aluminum alloy 6082 ; Full cone nozzle with cone angle $60^{\circ}$; Volume flow rate: $1.2 \mathrm{l} / \mathrm{min}$ 


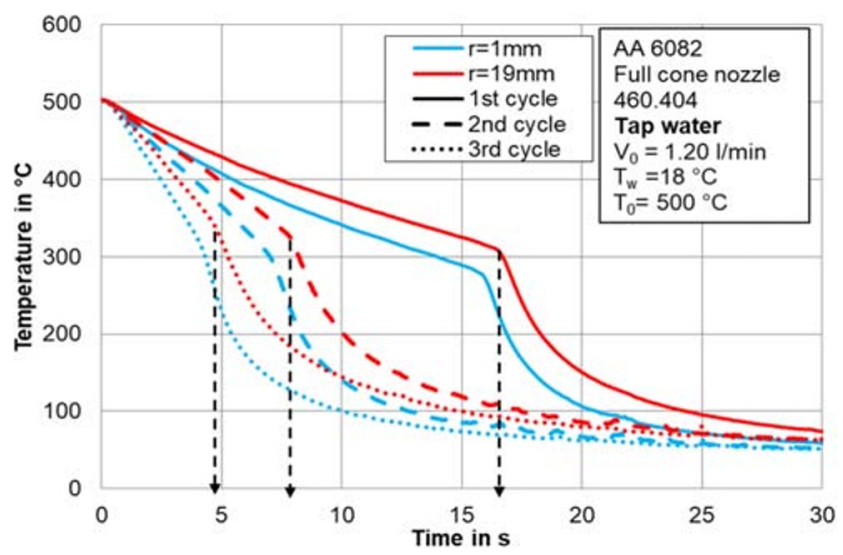

Fig. 8 Temperature curves for repeated cooling cycles with local tap water

is shown in Fig. 6. The produced surface cubic pins have the base area of $2 \mathrm{~mm} \times 2 \mathrm{~mm}$ and a height of $1 \mathrm{~mm}$, whose center distance is $4 \mathrm{~mm}$. If a center line is places on structure pit, the resulted mean roughness value of $R_{a}$ is $500 \mu \mathrm{m}$. Due to the uniformity of the structure, the maximum roughness $R_{\max }$ is identical to the values of the average roughness $R_{a}$. The plate thus produced serves as reference which has the highest roughness of a surface. A comparison with real casting surfaces should help to quantify the influence of roughness.
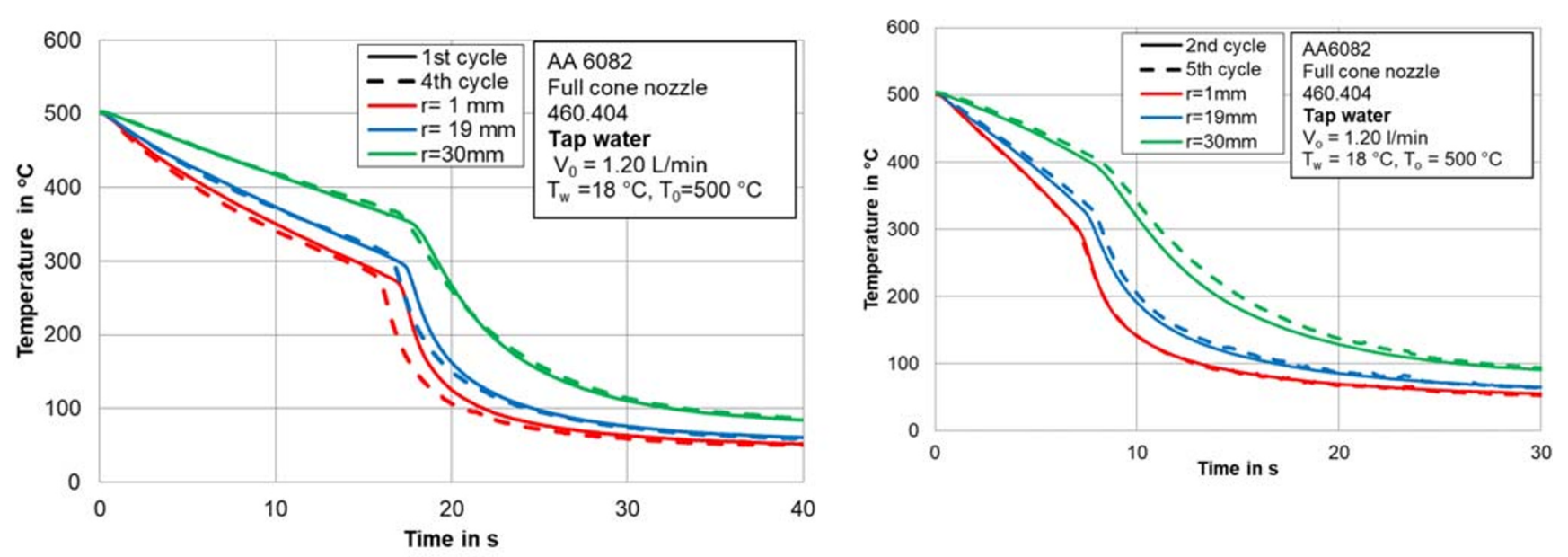

\section{Results and discussion}

\subsection{Repeatability of the experiments with full cone nozzle}

The experiments have been done to examine the repeatability of the experiments; since the amount of metal samples are limited. Some samples have to be used several times before disposed. Figure 7 shows the video and infrared images for repeated cooling cycles of a smooth surface of AA 6082 after a cooling time of $9 \mathrm{~s}$. Initially, the plate is brand new before heating in the furnace. The first cooling indicates the first subsequent cooling of this brand-new sample. The second cooling denotes the second cooling cycle with same sample after a second heating without any surface treatment. The same meaning stands for the third cooling. After a cooling time of $9 \mathrm{~s}$, no formation of wetted region can be observed in the first cooling which indicates the existence of the film boiling. At the same time, wetting and the formation of a wetted regions can be obtained in the second and third cooling cycle. Through the visual observation, the wetting front have progressed even further in the third cycle than the second. Same as the video recordings, the infrared recordings at the same cooling time also provides a qualitative analysis which

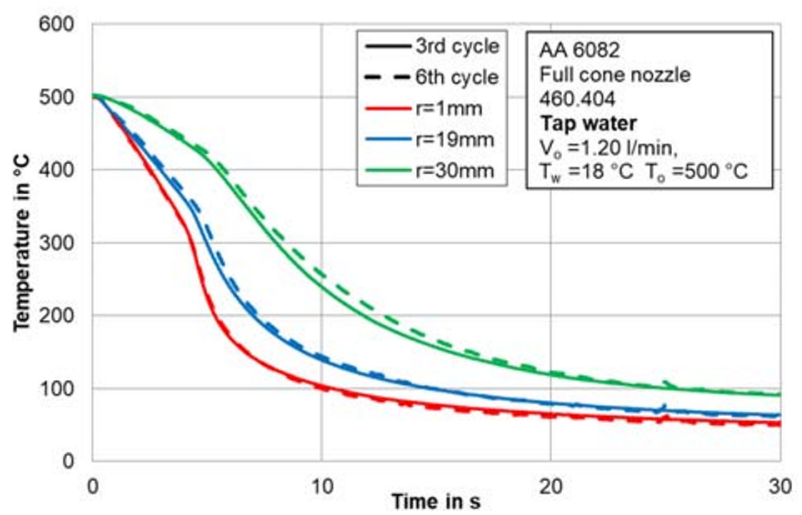

Fig. 9 Comparisons of temperature curves before and after surface treatment with emery paper 


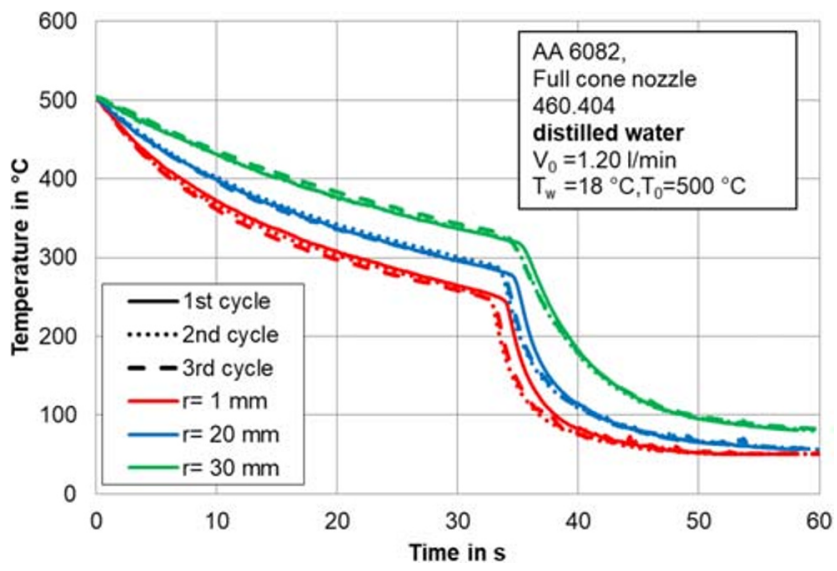

Fig. 10 Repeated cooling cycles with distilled water

demonstrates clearly that the cooling time shortens as the number of cooling cycle increases.

Additionally, the temperature curves at two radii for repeated cooling cycles are depicted in Fig. 8. It can be seen that cooling rate becomes faster with increasing cycle number. The film boiling takes place for approx. $16 \mathrm{~s}$ for the first cycle, reduced to $8.5 \mathrm{~s}$ in the second, followed by around $5 \mathrm{~s}$ in the third cycle. It is hypothesized that the surface conditions have been modified during the repeated cooling cycles by salt deposition in the white bear-belly shape which can be again found in the video images as shown in Fig. 7. Cui et al. [19] have studied the effects of dissolving gas and salts on heat transfer during droplet cooling. It was reported that the dissolved salts improve heat transfer when the surface temperature is above rewetting temperature due to the promotion of bubble formation by the salt concentrations. The similar tendency has been found in current research. A longer film boiling favors the salt deposition which will in turn leads to a faster cooling in the next repeated cycle. A direct verification of the hypothesis can be done by the surface structure examination by scanning electron microscope (SEM). Unfortunately, that was not done in the current research;

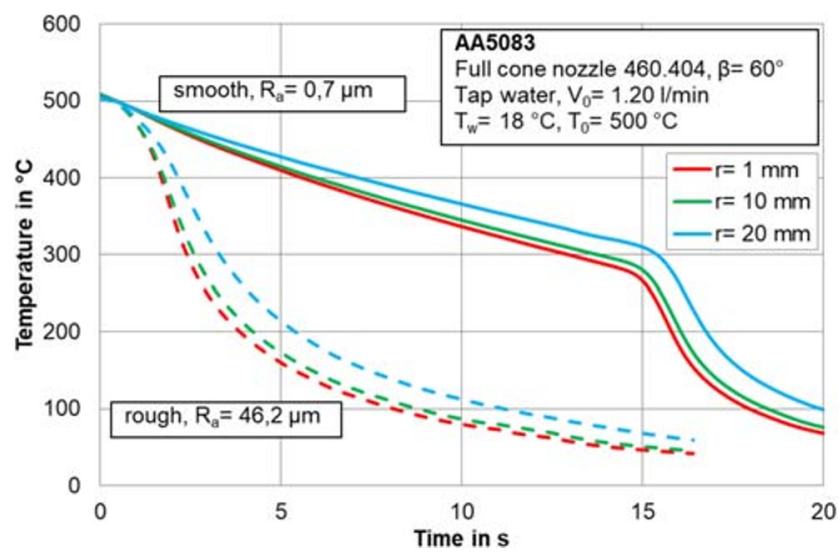

Fig. 11 Effect of surface roughness with full cone nozzle for AA 5083

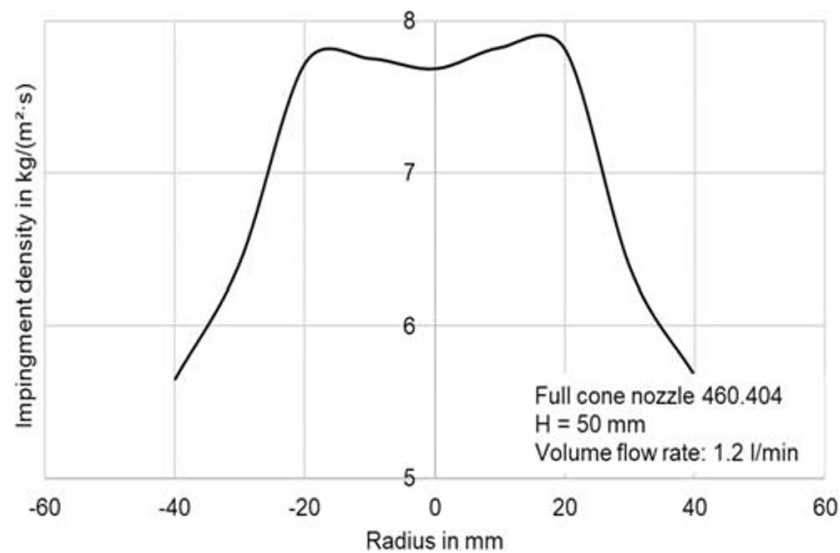

Fig. 12 Spray flux distribution with the used full cone nozzle

however, an indirect method has been used to strengthen the proposed statement.

After the third cooling, the surface on the quenching side was treated with emery paper carefully to remove the visible salt depositions. Meanwhile, the surface should be maintained as smooth as possible which avoids the influence of increased surface roughness by the manual treatment. Subsequently, another three cooling cycles were conducted which are denoted as 4th, 5th and 6th cooling cycles. The temperature profiles were then compared with previous cooling cycles on untreated surfaces; namely; 1 st vs. 4th, 2nd vs. 5th and 3rd vs. 6th. The comparisons are depicted in Fig. 9. It can be clearly observed that the cooling behavior can be well reproduced after a cautious treatment of the deposited salts. Furthermore, experiments with distilled water were carried out under the same experimental conditions. The results are shown in Fig. 10. The repetition of the experiments with the same metal sample shows no significant effect on the cooling time reduction. Through aforementioned experiments, the assumption of influence of salt deposition on cooling performance with full cone nozzle is indirectly validated.

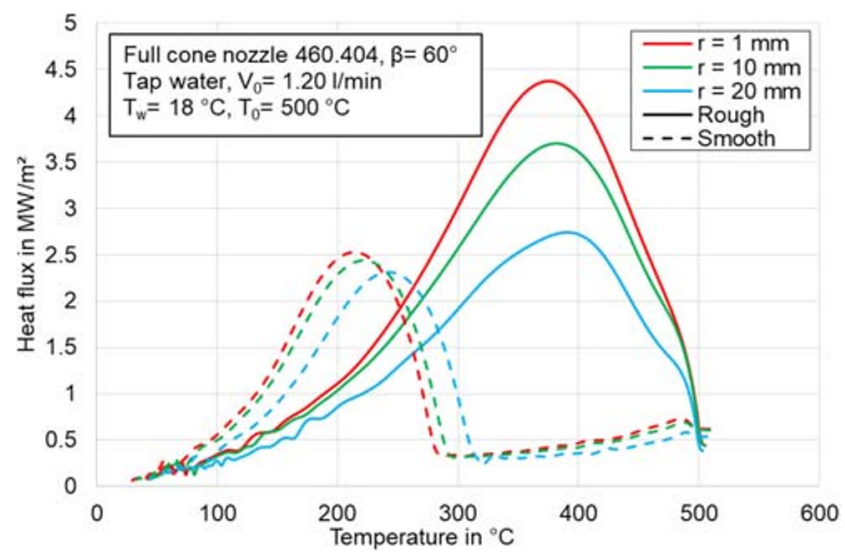

Fig. 13 Effect of surface roughness on boiling curves with full cone nozzle for AA 5083 


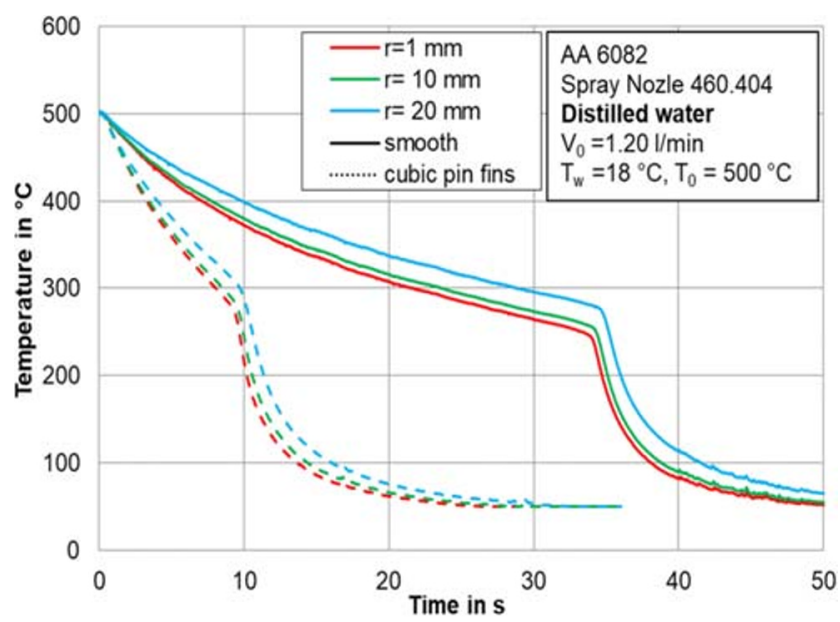

Fig. 14 Temperature comparison in cooling between smooth and cubic pin fin

\subsection{Effect of surface roughness with full cone nozzle}

Figure 11 exhibits the influence of roughness on temperature curves at different radii for aluminum alloy AA5083 with a spray nozzle. It is worth noting that the arithmetic roughness value $R_{a}$ in the casting direction is given in the figure, since the temperature values are extracted in the casting direction. The temperature deviates not so much at different radii which is in accordance with the spray flux distribution as shown in Fig. 12. On the other hand, the cooling rate increases dramatically with an increase of the arithmetic mean roughness $R_{a}$ from 0.7 to $46.2 \mu \mathrm{m}$. Based on a cooling end temperature of $100{ }^{\circ} \mathrm{C}$, the cooling time is reduced from approx. 20 to approx. $10 \mathrm{~s}$. These significant reductions in cooling time are also consistent with Abdalrahman's investigations [20], but the spray flux in his experiments was $3 \mathrm{~kg} / \mathrm{m}^{2} \mathrm{~s}$ and deionized water was used which led to a longer cooling time.

Meanwhile, it seems no apparent film boiling region can be observed for rough surface of AA 5083, which can be further evidenced in the boiling curves as shown in Fig. 13. 1. The determination of the heat flux is described in detail by

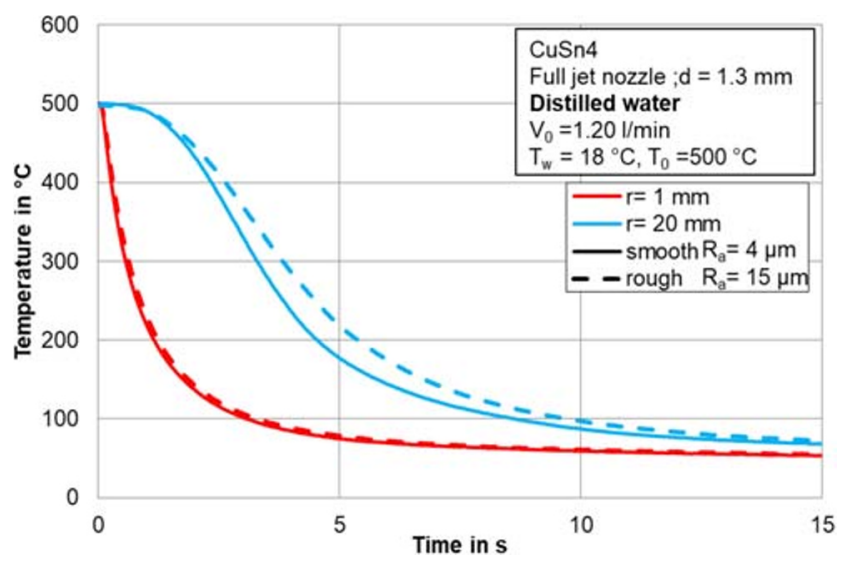

Fig. 15 Effect of surface roughness with full jet nozzle

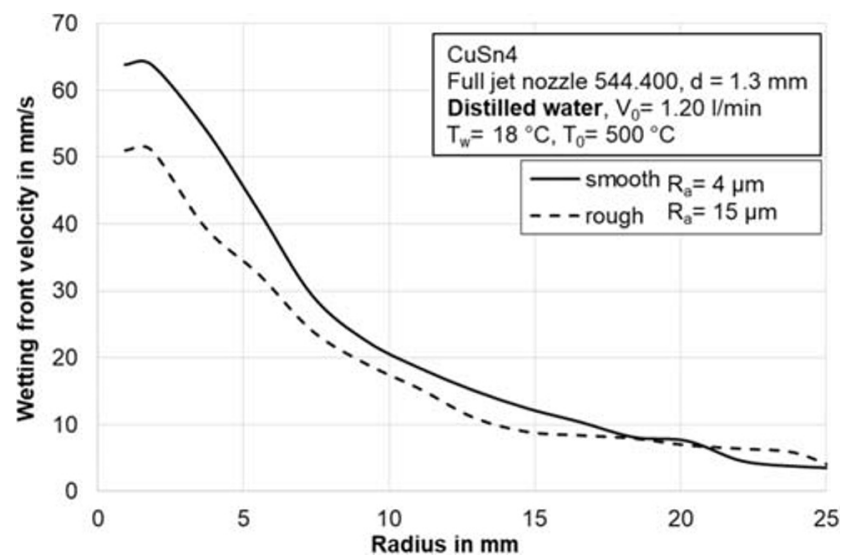

Fig. 16 Effect of roughness on wetting front propagation with full jet nozzle

Sabariman [21, 22] and Nallathambi and Specht [23]. The first step is to calculate heat flux from a one-dimensional energy balance model, where the temperature difference in the thickness is neglected. This result acts then as an initial guess for the inverse solution of the Fourier-differential equation to calculate the temperature on the measuring side. The accuracy of determination of heat flux using this method is within $3 \%$ for aluminum alloys; and within $8 \%$ for $\mathrm{CuSn} 4$. The heat flux increases dramatically when the cooling is initiated for the rough surfaces which indicates an immediate rewetting once the whole spray impacts the hot surface, resulting a shorter transition boiling region, higher rewetting and DNB temperatures and higher heat transfer rate. One explanation could be that these rough elements acted as microstructures and enhanced the heat transfer rate from the vapor to the bulk liquid. If the transition boiling region is assumed as combination of transition and nucleate boiling, then it is also possible that the surface roughness increases nucleation site density at a given surface temperature in transition boiling which shortens its period.

The maximum heat flux for rough surface is around 4.5 MW/ $\mathrm{m}^{2}$ at radius of $1 \mathrm{~mm}$, whereas the maximum value

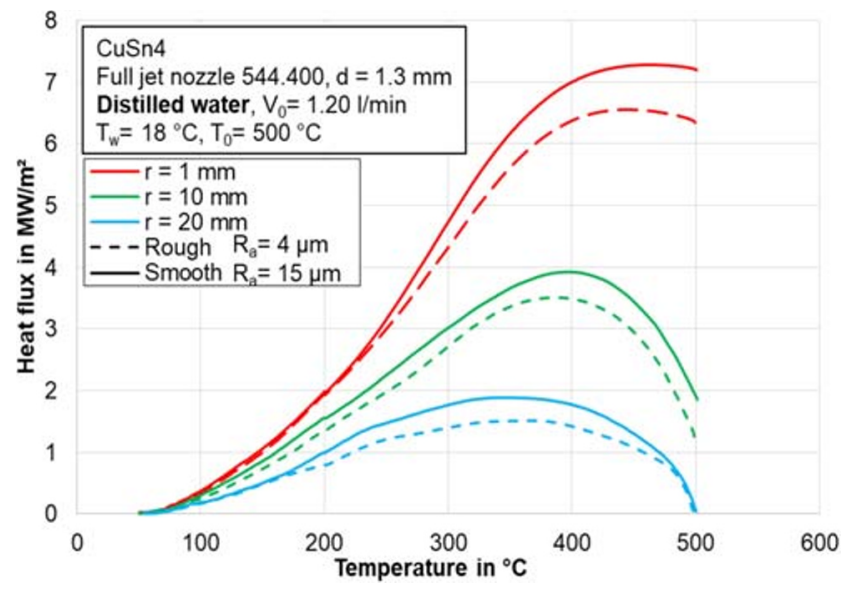

Fig. 17 Boiling curves for distilled water with full jet nozzle 
Fig. 18 Photo of the mold used in this work ((left) front view; (right) side view): 1 . water supply, 2. Orifices, 3 . Adjustable screw for angle variation, 4 . Supporting rods

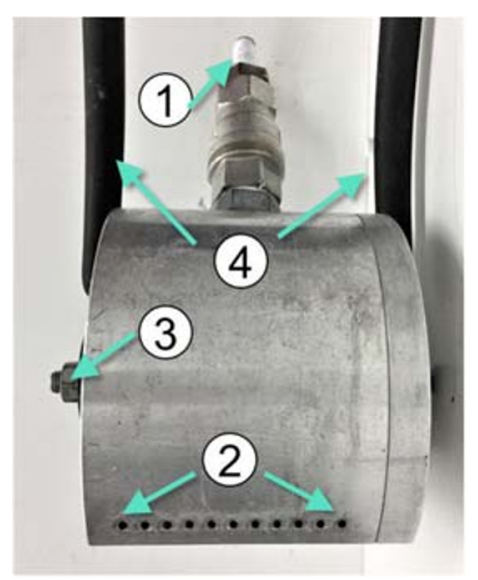

for smooth surface is only $2.5 \mathrm{MW} / \mathrm{m}^{2}$. This suggests clearly that increasing surface roughness helps to enhance the cooling efficiency by using a full cone nozzle.

The investigation of artificial surface follows the previous studies. A sample with one-sided artificially structured surface was produced by mechanical processing from the same metal batch of aluminum alloy AA6082 which were directly bought from the metal dealer. The technical details of the produced surfaces is depicted in Fig. 6.

In Fig. 14 cooling curves measured for both smooth and artificially structured surface are compared. The smooth surface cooling curves have solid lines while the rough surface cooling curves are in dashed lines. A significant reduction of the cooling time with a structured surface can be recognized which again indicates that the roughness of the surface promotes faster cooling. Typical cooling curves can be observed when film boiling occurs. Initially the temperature decreases approximately linearly in course of cooling until a temperature of about 280 to $300{ }^{\circ} \mathrm{C}$ is reached, and then a higher cooling gradient is expected. This transition suggests the transition from film boiling to transition boiling and is shown on the quenching side by the abrupt rewetting of the surface.

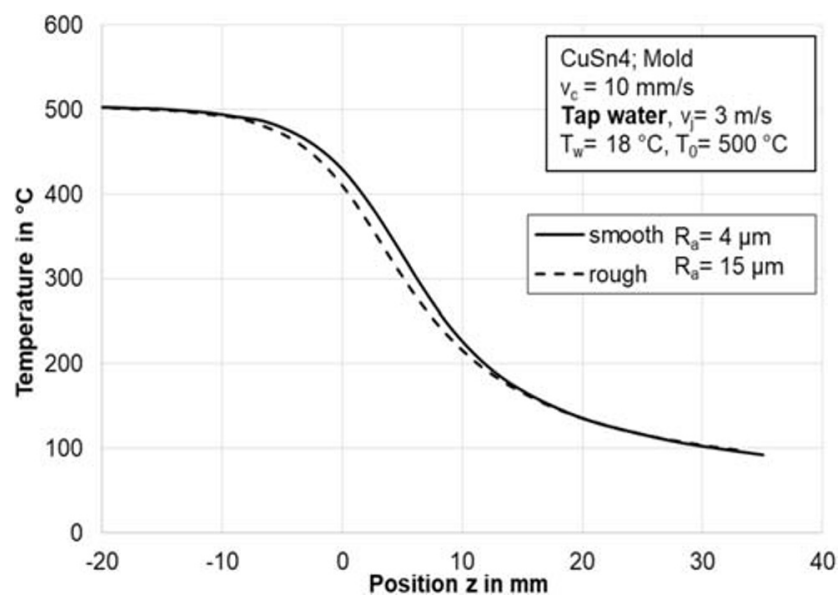

Fig. 19 Effect of surface roughness on temperatures with mold cooling

\subsection{Effect of surface roughness with full jet nozzle}

In this section, the influence of surface roughness on cooling performance during the application of a single full jet nozzle will be presented. By far, in the open literatures, this area is not studied to the best of my knowledge.

If a full jet impacts the copper alloy CuSn4, no change in the cooling performance at the stagnation region is to be determined as a function of the arithmetic mean roughness $R_{a}$ (Fig. 15). At a radius of $20 \mathrm{~mm}$ from the stagnation point, the rougher surface of $R_{a}=14.7 \mu \mathrm{m}$ is cooled even slower. This is explained by the fact that the rougher surface opposes the propagation of the wetting front, although evaporation at wetting front is more intensive for the rougher surface. To better clarify the differences, the wetting front propagation for both types of water is shown in Fig. 16.

The wetting front on rough surface propagates slower than on smooth surface which further indicates the opposition effect of surface roughness on wetting front propagation. Figure 17 depicts the corresponding local boiling curves for both water types. Generally, the heat flux is slightly higher for smooth surfaces.

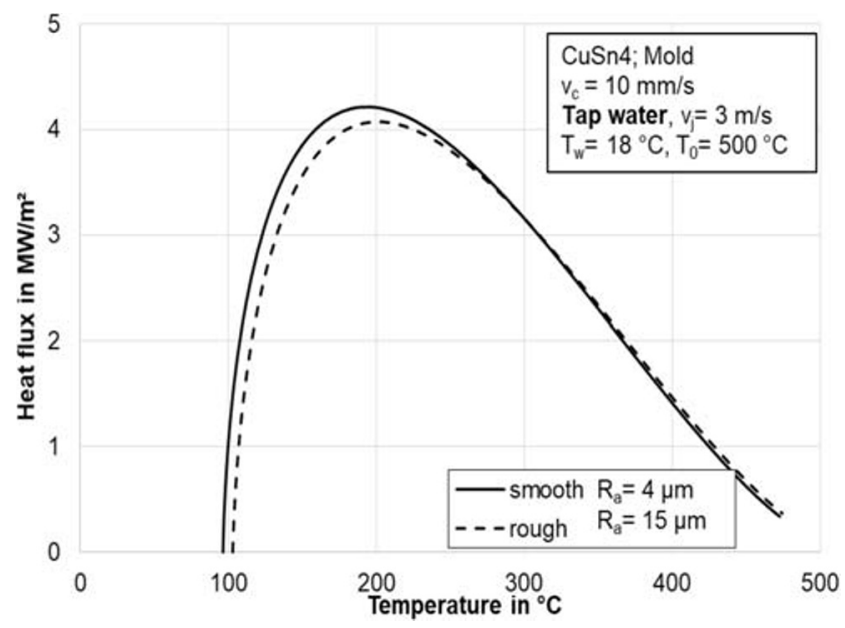

Fig. 20 Effect of surface roughness on boiling curves with mold cooling 

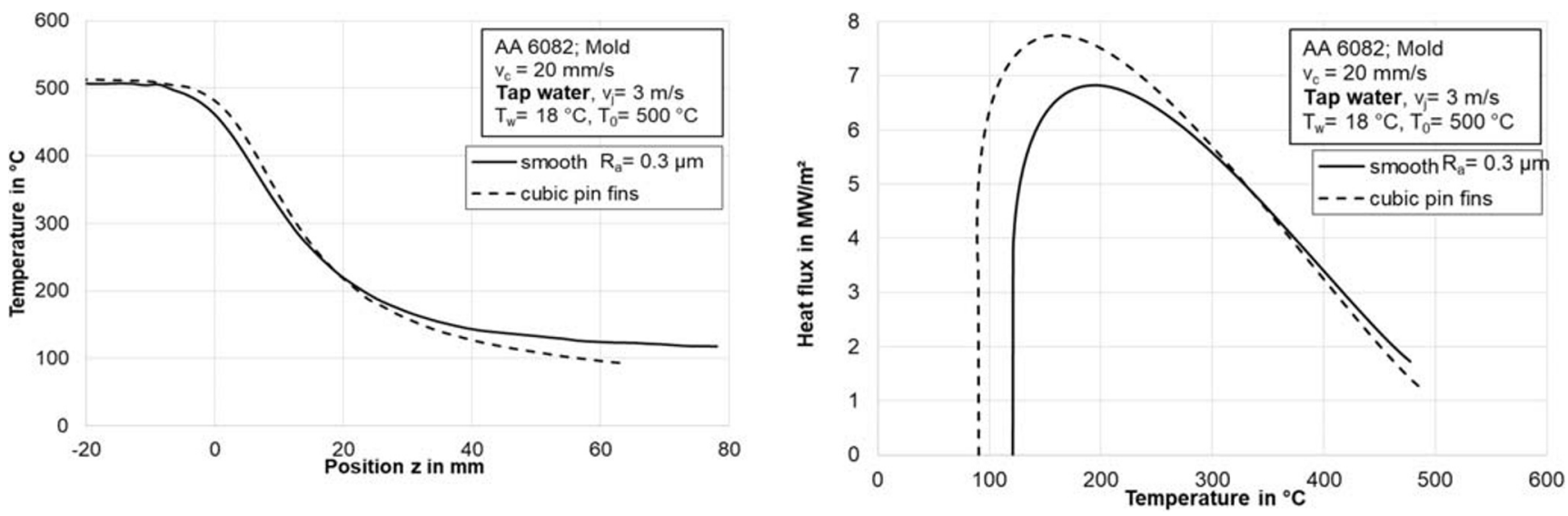

Fig. 21 Effect of surface roughness on temperatures and boiling curves with mold cooling of AA 6082

\subsection{Effect of surface roughness with mold}

In order to mimic the industrial application of direct chill (DC) casting, especially the secondary cooling regime, a house made miniature is used. The detailed description of the mold can be found in Fig. 18. It has 11 orifices at its base, each of $2 \mathrm{~mm}$ in diameter. Hence, it can be also regarded as a row of liquid jets.

Figure 19 depicts the influence of surface roughness on cooling when $\mathrm{CuSn} 4$ is investigated. A slight difference between two surfaces can be observed, especially in the transition and nucleate cooling region, which is further illustrated as boiling curves in Fig. 20. The plate moves continually downward at preset velocity while the mold remains fixed. This enables the liquid jets always to impinge on the fresh untouched surfaces, which avoids the possibility of effect of deposited salt on the surface. Furthermore, high momentum of the impinging liquid jets compensates more intensive evaporation on the rough surfaces by sweeping the nucleated bubbles faster away. These two factors together make mold cooling insensitive to the surface roughness created during industrial manufacturing.

The results for the artificial structure of cubic pin fins are shown in Fig. 21. The theoretical arithmetic mean roughness $R_{a}$ is $250 \mu \mathrm{m}$. When the cooling temperature is higher than $200{ }^{\circ} \mathrm{C}$, the deviations are marginal; however, at temperatures below $200{ }^{\circ} \mathrm{C}$, the roughness begins to play a major role. This can be further ascertained in the boiling curves. The maximum heat flux for structures surface is approx. $8 \mathrm{MW} / \mathrm{m}^{2}$, while $7 \mathrm{MW} / \mathrm{m}^{2}$ for smooth surfaces. The difference in this case is mainly contributed by the water accumulation between the fins. The accumulated water enables a longer contact between the hot surface and the cooling medium, namely, water, which inevitably enhances the heat transfer rate. This phenomenon insights the possibility of enhancement of cooling rate by structured surfaces when a relative movement between the cooling medium and the surface exists.

\section{Conclusion}

The effect of surface roughness on cooling behavior during quenching hot metals are experimentally investigated. Hereby, the single nozzle such as full cone and full jet nozzle and a mold are utilized to quench the samples. The rough surfaces are provided from the industry and the surface condition remains as produced; meanwhile, an artificial structure is produced to be used as comparison. The characteristics of all the rough surfaces are measured with a stylus profilometer.

It is found out that the effect of surface roughness is most paramount in application of full cone nozzles. Even with a slight increase of arithmetic mean roughness $R_{a}$, the cooling time can be reduced dramatically. However, the effect of surface roughness is not that significant in case of full jet and mold cooling. A clear conclusion can be drawn though these three series of tests: a cooling method which promotes film boiling is much more sensitive to the variation of surface conditions, since the produced rough surface elements in industry are in general larger than the film thickness in the film boiling region. This enables intermittent direct contact between liquid and hot surface which reduces the cooling time significantly. However, this is not directly proved with experimental observations, which requires further measurements of the liquid film thickness.

Acknowledgements This study of the German Federation of Industrial Research (IGF BR 03244) has been promoted by the Research Association of Nonferrous Metals (Stifterverband Metalle e. V.) and funded by the Federal Ministry of Economics and Technology. Open Access funding provided by Projekt DEAL.

Open Access This article is licensed under a Creative Commons Attribution 4.0 International License, which permits use, sharing, adaptation, distribution and reproduction in any medium or format, as long as you give appropriate credit to the original author(s) and the source, provide a link to the Creative Commons licence, and indicate if changes were made. The images or other third party material in this article are included in the article's Creative Commons licence, unless indicated otherwise in a credit line to the material. If material is not included in the article's 
Creative Commons licence and your intended use is not permitted by statutory regulation or exceeds the permitted use, you will need to obtain permission directly from the copyright holder. To view a copy of this licence, visit http://creativecommons.org/licenses/by/4.0/.

\section{References}

1. Labergue A, Gradeck M, Lemoine FJIJoH, Transfer M (2015) Comparative study of the cooling of a hot temperature surface using sprays and liquid jets 81:889-900

2. Alam U, Krol J, Specht E, Schmidt J (2010) Enhancement and local regulation of metal quenching using atomized spraysQuenching and cooling, Residual Stress and Distortion Control ASTM International

3. Mudawar I, Valentine WJJoHT (1989) Determination of the local quench curve for spray-cooled metallic surfaces 7:107-121

4. Karwa N, Stephan PJIJoH, Transfer M (2013) Experimental investigation of free-surface jet impingement quenching process 64 : $1118-1126$

5. Wang H, Wu J, Yang Q, Zhu X, Liao QJJoH, Transfer M (2016) Heat transfer enhancement of ammonia spray cooling by surface modification 101:60-68

6. Lee Y, Shen W-Qljoh, Transfer M (1985) Effect of coolant vapor quality on rewetting phenomena 28:139-146

7. Mozumder AK, Monde M, Woodfield PL, Islam MAJIJoH, Transfer M (2006) Maximum heat flux in relation to quenching of a high temperature surface with liquid jet impingement 49 : 2877-2888

8. Pais M, Chow L, Mahefkey EJJoHT (1992) Surface roughness and its effects on the heat transfer mechanism in spray cooling 114:211219

9. Bernardin JD, Mudawar IJJoem, technology (1996) An experimental investigation into the relationship between temperature-time history and surface roughness in the spray quenching of aluminum parts 118:127-134

10. Sinha JJEht (2003) Effects of surface roughness, oxidation level, and liquid subcooling on the minimum film boiling temperature 16 : 45-60

11. Silk EA, Kim J, Kiger K (2004) Investigation of enhanced surface spray cooling 685-690. doi: https://doi.org/10.1115/IMECE200461753
12. Silk EA, Kim J, Kiger KJJJoH, Transfer M (2006) Spray cooling of enhanced surfaces: impact of structured surface geometry and spray axis inclination 49:4910-4920

13. Sodtke C, Stephan PJJJoH, Transfer M (2007) Spray cooling on micro structured surfaces50:4089-4097

14. Xu R, Li L, Zhang L, Zhu B, Liu X, Bu XJJoMPT (2014) Influence of pressure and surface roughness on the heat transfer efficiency during water spray quenching of 6082 aluminum alloy 214:28772883

15. Aamir M, Liao Q, Hong W, Xun Z, Song S, Sajid MJH, Transfer M (2017) Transient heat transfer behavior of water spray evaporative cooling on a stainless steel cylinder with structured surface for safety design application in high temperature scenario 53:363-375

16. Fang Y, Specht E (2018) Heat transfer analysis during jet impingement on metal plates, International Heat Transfer Conference 16 (IHTC16), pp 2323-2331, Beijing, China, 10-15 August

17. Fang Y (2019) Influence of nozzle type and configuration and surface roughness on heat transfer during metal quenching with water, $\mathrm{PhD}$ thesis in Process and System Engineering Faculty, Otto-vonGuericke-Universität Magdeburg

18. Dubbel H (2013) DUBBEL: Taschenbuch für den Maschinenbau Springer-Verlag

19. Cui Q, Chandra S, McCahan SJJoht (2001) The effect of dissolving gases or solids in water droplets boiling on a hot surface 123:719728

20. Abdalrahman KHM (2012) Influence of water quality and kind of metal in the secondary cooling zone of casting process Universitätsbibliothek

21. Sabariman (2015) Heat Transfer Analysis in Metal Quenching with Sprays and Jets Docupoint-Verlag

22. Sabariman, Specht E (2018) Characterization of the boiling width on metal quenching with spray cooling. Exp Heat Transfer 31:391404

23. Nallathambi AK, Specht E (2009) Estimation of heat flux in array of jets quenching using experimental and inverse finite element method. J Mater Process Technol 209:5325-5332

Publisher's note Springer Nature remains neutral with regard to jurisdictional claims in published maps and institutional affiliations. 